\title{
Geographical variation and factors associated with colorectal cancer mortality in a universal health care system
}

\author{
Mahmoud Torabi $\mathrm{PhD}^{1}$, Christopher Green $\mathrm{PhD}^{1}$, Zoann Nugent $\mathrm{PhD}^{1,2,3}$, Salaheddin M Mahmud PhD ${ }^{1,3}$, \\ Alain A Demers $\mathrm{PhD}^{1,3}$, Jane Griffith $\mathrm{PhD}^{1,3}$, Harminder Singh MD MPH FACG ${ }^{1,2,4,5}$
}

M Torabi, C Green, Z Nugent, et al. Geographical variation and factors associated with colorectal cancer mortality in a universal health care system. Can J Gastroenterol Hepatol 2014;28(4): 191-197.

OBJECTIVE: To investigate the geographical variation and small geographical area level factors associated with colorectal cancer (CRC) mortality.

METHODS: Information regarding CRC mortality was obtained from the population-based Manitoba Cancer Registry, population counts were obtained from Manitoba's universal health care plan Registry and characteristics of the area of residence were obtained from the 2001 Canadian census. Bayesian spatial Poisson mixed models were used to evaluate the geographical variation of CRC mortality and Poisson regression models for determining associations with CRC mortality. Time trends of CRC mortality according to income group were plotted using joinpoint regression.

RESULTS: The southeast (mortality rate ratio [MRR] 1.31 [95\% CI 1.12 to 1.54 ) and southcentral (MRR 1.62 [95\% CI 1.35 to 1.92$]$ ) regions of Manitoba had higher CRC mortality rates than suburban Winnipeg (Manitoba's capital city). Between 1985 and 1996, CRC mortality did not vary according to household income; however, between 1997 and 2009, individuals residing in the highest-income areas were less likely to die from CRC (MRR 0.77 [95\% CI 0.65 to 0.89]). Divergence in CRC mortality among individuals residing in different income areas increased over time, with rising CRC mortality observed in the lowest income areas and declining CRC mortality observed in the higher income areas.

CONCLUSIONS: Individuals residing in lower income neighbourhoods experienced rising CRC mortality despite residing in a jurisdiction with universal health care and should receive increased efforts to reduce CRC mortality. These findings should be of particular interest to the provincial CRC screening programs, which may be able to reduce the disparities in $\mathrm{CRC}$ mortality by reducing the disparities in CRC screening participation.

Key Words: Colorectal cancer mortality; Spatial patterns; Universal health care; Worsening socioeconomic disparities

Oolorectal cancer (CRC) continues to be the second most common cause of cancer deaths in North America (1), although many of these deaths could be prevented by removal of precancerous precursor lesions or by detection of CRC at early and curable stages $(2,3)$. Although there has been a recent emphasis on lowering the incidence of CRC, reduction in CRC mortality is the primary objective of CRC screening activities. An apparent increase in incidence is witnessed after the initiation of screening programs due to the identification of prevalent cases and, subsequently, due to overdiagnosis of indolent cases, inherent in most screening activities (4). Hence, CRC

\section{La variation géographique et les facteurs associés à la mortalité causée par le cancer colorectal dans un système de santé universel}

OBJECTIF : Examiner la variation géographique et les facteurs liés à une petite région géographique associés à la mortalité causée par le cancer colorectal (CCR).

MÉTHODOLOGIE : Les chercheurs ont obtenu l'information relative à la mortalité causée par le CCR dans le Registre du cancer du Manitoba (un registre en population), le décompte de la population dans le registre d'assurance-maladie universelle du Manitoba et les caractéristiques des régions de résidence dans le recensement du Canada de 2001. Ils ont utilisé des modèles bayésiens mixtes de Poisson avec généralisation spatiale pour évaluer la variation géographique de la mortalité causée par le CCR et des modèles de régression de Poisson pour déterminer les associations avec la mortalité causée par le CCR. Ils ont consigné les tendances de la mortalité causée par le CCR dans le temps selon le groupe de revenu d'après la régression Joinpoint.

RÉSULTATS : Les régions du sud-est (ratio des taux de mortalité [RTM] 1,31 [95 \% IC 1,12 à 1,54) et du centre-sud (RTM 1,62 [95\% IC 1,35 à 1,92]) du Manitoba présentaient des taux de mortalité causée par le CCR plus élevés que la région suburbaine de Winnipeg (capitale du Manitoba). Entre 1985 et 1996, le taux de mortalité causée par le CCR ne variait pas selon le revenu familial, mais entre 1997 et 2009, les personnes qui habitaient dans les régions au revenu le plus élevé étaient moins susceptibles de mourir d'un CCR (RTM 0,77 [95\% IC 0,65 à 0,89]). La divergence du taux de mortalité causée par le CCR chez les personnes qui habitent dans des régions aux revenus variés augmentait au fil du temps, le taux de mortalité causée par le CCR s'accroissant dans les régions à faible revenu et diminuant dans les régions au revenu le plus élevé.

CONCLUSIONS : Les personnes qui habitaient dans des quartiers à faible revenu présentaient un taux de mortalité croissant causée par le CCR, même si le système de santé universel était offert dans leur territoire de compétence et aurait dû s'associer à plus d'efforts pour réduire la mortalité causée par le CCR. Ces observations devraient susciter l'intérêt des programmes provinciaux de dépistage du CCR, qui pourront peutêtre réduire les disparités en matière de mortalité causée par le CCR en atténuant les écarts de participation au dépistage du CCR.

mortality remains the primary outcome of interest for public health programs aiming to reduce the burden of CRC and, accordingly, was the focus of the present study.

Exploring geographical variation in CRC mortality and predictors of CRC mortality could help in developing risk-tailored approaches for CRC screening by rapidly expanding CRC screening programs. Several studies have investigated the variation in CRC mortality among small geographical areas, but few explored the effect of socioeconomic factors in jurisdictions with universal health care systems such as Canada $(5,6)$. Universal health care systems are expected to

${ }^{1}$ Department of Community Health Sciences; ${ }^{2}$ University of Manitoba IBD Clinical and Research Centre, University of Manitoba; ${ }^{3}$ Department of

Epidemiology and Cancer Registry; ${ }^{4}$ Department of Hematology and Oncology, CancerCare Manitoba; ${ }^{5}$ Department of Internal Medicine, University

of Manitoba, Winnipeg, Manitoba

Correspondence: Dr Harminder Singh, Section of Gastroenterology, University of Manitoba, 805-715 McDermot Avenue, Winnipeg, Manitoba R3E 3P4.

Telephone 204-480-1311, fax 204-789-3972, e-mail harminder.singh@med.umanitoba.ca

Received for publication February 5, 2014. Accepted February 7, 2014 
provide equitable access to health care services to different sections of the population and, thereby, reduce disparities in disease outcomes such as CRC mortality. Review of outcomes in such health care systems is of increasing relevance, even to the jurisdictions without such systems (such as the United States) because they are initiating programs aiming to increase health care coverage in their populations.

Manitoba, a central Canadian province, has a universal health care plan without premiums that covers all residents irrespective of their age or socioeconomic status (SES) (7). In addition, efforts are continuously made to reduce any potential disparities in access to health care services across the province (eg, providing diagnostic imaging such as computed tomography scanning and onsite chemotherapy at remote areas in the province). We hypothesized that CRC mortality rates would be comparable across the different socioeconomic strata in the province and would change at a comparable rate over time.

The objectives of the current study were to determine the geographical and temporal variation in CRC mortality in Manitoba and to identify population-level factors associated with CRC mortality.

\section{METHODS}

\section{Data sources and study measures}

Manitoba is a central Canadian province with a relatively stable population (1.11 million in 1985 and 1.21 million in 2009). Manitoba Health is the publicly funded health insurance agency providing comprehensive universal health insurance to all residents of Manitoba (except inmates, and members of the Armed Forces and Royal Canadian Mounted Police) and maintains a population registry of permanent residents in the province. The population registry is a demographic, vital status and migration status database, and was used to determine the population size and distribution across the province.

Information regarding deaths from CRC was obtained from the Manitoba Cancer Registry (MCR), a population-based database actively recording all cancers diagnosed in residents of the province since 1956. Reporting to the MCR is mandated by law. The coding and capture of cancer data are audited regularly by the North American Association of Central Cancer Registries and the Canadian Cancer Registry. The quality of the MCR data is high, with consistently high levels of reporting completeness and histological verification $(8,9)$. The MCR receives reports from Manitoba Vital Statistics on cause of death and investigates and documents all cases in which the reported cause of death is cancer.

Information regarding cause and date of death was obtained from the MCR for all Manitoba residents who died from CRC between 1985 and 2009, and who had a diagnosis of CRC. Cases of CRC were identified using International Classification of Diseases, Ninth Revision, Clinical Modification (ICD-9-CM) codes 153.0-153.4, 153.6-154.1 and 159.0 (for cases diagnosed before 2002) and ICD-10-CA codes C18.0, C18.2-C18.9, C19, C20 and C26.0 (from 2002 onward). Also included were CRC patients whose cause of death was listed as another cancer (lung, liver, primary unknown) but had no record of diagnosis of a cancer other than CRC.

There are differences in the biology and phenotype of CRC occurring in the proximal (upper/right) part of the colon compared with those occurring in the distal (lower/left) colon $(10,11)$. Several recent studies suggest that in routine clinical practice, all commonly used CRC screening tests are less effective in reducing proximal CRC incidence and mortality (12-15). The incidence of CRC occurring in the proximal part of the colon has been increasing in Canada (16). Therefore, geographical variation in mortality due to proximal colon CRCs (cancers occurring in and proximal to the splenic flexure) and distal colon CRCs (cancers distal to the splenic flexure) were determined separately. To determine the CRC subsite, the subsite at the time of cancer diagnosis as recorded in the MCR was used.

A combination of the six-digit postal code and the municipal code of residence at time of diagnosis was used to geocode each CRC death to one of the 230 neighbourhoods in Winnipeg (average population during the study years 653,100 ) or to one of the 268 municipalities in rural Manitoba (average population during the study years 500,977). For the population included in the denominator, the residential codes used were those recorded on July 1 of each year. These 498 areas were the geographical units used in the analyses. Areas within Winnipeg the only urban centre in Manitoba with a population $>50,000$ - were considered to be urban. All other areas were considered to be rural. Sociodemographic characteristics, such as mean household income, proportion of recent immigrants, Jewish ethnicity (increased CRC incidence has been reported in some studies among those of Jewish ethnicity [17]), visible minority status and unemployment status, were obtained for each area from the 2001 Canadian census microdata files.

\section{Statistical analysis}

To visualize geographical variation in CRC mortality, a spatial Poisson mixed model was used to calculate age- and sex-standardized rates, using the 1991 general Canadian population as the standard. To control for potentially unstable rate estimates resulting from small case counts in areas with small populations, rate estimates were smoothed using Bayesian spatial Poisson hierarchical models incorporating two random variables indicating geographical variation and any other unspecified variation across study areas (15). Using hierarchical models, the mortality rate in each area is smoothed by pooling information from the neighbouring areas to generate stable rate estimates (18). Details of the Bayesian models used in this analysis are discussed elsewhere (19). The deviance information criterion was used for model diagnostics. ArcGIS version 10.0 (Environmental Systems Research Institute, USA) was used to produce choropleth maps of rates.

To model the relationship between CRC mortality and the characteristics of the geographical units, two approaches were taken, both using age- and sex-adjusted Poisson regression models. First, a series of Bayesian Poisson regression models were implemented for each characteristic with adjustment for age and sex to control for differences in demographic structures. Second, a saturated Bayesian Poisson regression model containing multiple predictor variables was developed. All models were fitted to individual cases, whereby cases were assigned the ecological characteristics (eg, average income level) of the geographical unit to which they were geocoded. Variables were categorized using Jenks natural breaks classification method, which attempts to find natural break points in the data when identifying category cut-offs (20). In the saturated model, a variable for the region of residence in the province (Winnipeg urban core; Winnipeg areas outside the urban core [suburban]; Northern Manitoba, Southwestern Manitoba, Southcentral Manitoba; and Southeastern Manitoba) was included. Some of the ecological variables, such as the proportion of Jewish or visible minorities and urban/rural residence, were not included in the saturated model to avoid multicollinearity. Potential overdispersion in the models was managed by incorporating a random variable to capture unspecified variation across small areas. The results are based on posterior probability and presented as mortality rate ratios (MRR) and corresponding $95 \%$ credible intervals (equivalent to confidence intervals in non-Bayesian analyses). The WinBUGS software package (MRC Biostatistics unit, Institute of Public Health, United Kingdom) was used for all Bayesian analyses.

All analyses (choropleth maps and regression models) were separately repeated for proximal and distal colon CRC mortality and for two different periods (1985 to 1996; 1997 to 2009). The year 1997 has been previously noted to be the year with potentially sharper increase in CRC screening in the province (16) and the year at which CRC mortality started decreasing in Canada (21).

To further explore the findings of the main Bayesian analyses, the linear time trends of CRC mortality in the different income groups were assessed by the Joinpoint Regression program developed by SEER (Surveillance Epidemiology and End Results, National Cancer Institute, USA). The average annual percentage changes (APC) in CRC mortality were calculated. The APC gives the estimated average annual rate of change in the rates and is equal to $100 *\left(\mathrm{e}^{\mathrm{m}}-1\right)$, in which $\mathrm{m}$ is the slope of the corresponding regression line. The $\mathrm{P}$ value 
Spatial patterns and predictors of CRC mortality

TABLE 1

Colorectal cancer mortality counts and rates (per 100,000) according to site, sex and age, 1985 to 2009

\begin{tabular}{|c|c|c|c|c|c|c|c|c|c|c|c|c|}
\hline \multirow{3}{*}{$\begin{array}{l}\text { Age group, } \\
\text { years }\end{array}$} & \multicolumn{4}{|c|}{ Overall mortality } & \multicolumn{4}{|c|}{ Distal colon } & \multicolumn{4}{|c|}{ Proximal colon } \\
\hline & \multicolumn{2}{|c|}{ Female } & \multicolumn{2}{|c|}{ Male } & \multicolumn{2}{|c|}{ Female } & \multicolumn{2}{|c|}{ Male } & \multicolumn{2}{|c|}{ Female } & \multicolumn{2}{|c|}{ Male } \\
\hline & Count & Rate & Count & Rate & Count & Rate & Count & Rate & Count & Rate & Count & Rate \\
\hline Overall & 3411 & 23.4 & 3838 & 26.9 & 1695 & 11.6 & 2313 & 16.2 & 1262 & 8.6 & 1146 & 8.0 \\
\hline$<50$ & 139 & 1.4 & 169 & 1.6 & 84 & 0.8 & 106 & 1.0 & 44 & 0.4 & 47 & 0.4 \\
\hline $50-69$ & 906 & 32.1 & 1348 & 49.7 & 515 & 18.2 & 863 & 31.8 & 317 & 11.2 & 369 & 13.6 \\
\hline$\geq 70$ & 2366 & 155.7 & 2321 & 228.8 & 1096 & 72.1 & 1344 & 132.5 & 901 & 59.3 & 730 & 72.0 \\
\hline
\end{tabular}

TABLE 2

Time trends in overall colorectal cancer mortality rate according to sex and income

\begin{tabular}{|c|c|c|c|c|c|}
\hline \multirow[b]{2}{*}{ Annual income, \$ } & \multirow[b]{2}{*}{ Time period } & \multirow[b]{2}{*}{$\operatorname{APC}(\mathrm{P})$} & \multirow{2}{*}{$\begin{array}{c}\text { Pairwise } \\
\text { comparisons }\end{array}$} & \multicolumn{2}{|c|}{ P for pairwise comparisons* } \\
\hline & & & & Coincident & Parallel \\
\hline \multicolumn{6}{|l|}{ Men } \\
\hline All & 1985-2009 & $-0.41(0.48)$ & & & \\
\hline 47,000 to 85,000 (average) & 1985-2009 & $-0.44(0.19)$ & Low versus average & $<0.01$ & $<0.01$ \\
\hline$>85,000$ (high) & 1985-2009 & $-1.83(0.03)$ & Average versus high & 0.04 & 0.15 \\
\hline \multicolumn{6}{|l|}{ Women } \\
\hline \multirow[t]{2}{*}{$<47,000$ (low) } & 1985-1992 & $+8.07(0.01)$ & Low versus high & 0.01 & 0.02 \\
\hline & 1992-2009 & $+0.04(0.94)$ & & & \\
\hline 47,000 to 85,000 (average) & 1985-2009 & $-0.63(0.05)$ & Low versus average & $<0.01$ & $<0.01$ \\
\hline$>85,000$ (high) & 1985-2009 & $-1.86(0.07)$ & Average versus high & 0.38 & 0.20 \\
\hline
\end{tabular}

*The test of coincidence assesses whether two Joinpoint regression functions are identical and the test of parallelism assesses whether the two regression mean functions are parallel

presented with the APC estimates assesses the statistical significance of the estimates slope derived from the log-linear regression model. Pairwise comparability tests were performed to compare the different sets of trend data (22).

\section{RESULTS}

The number of deaths from CRC totalled 7249 between 1985 and 2009 , with an average of 25.1 fatalities per 100,000 population per year (Table 1). The number of deaths from distal and proximal colon CRCs was 4008 and 2408, respectively. The annual mortality rates (per $100,000)$ from distal colon CRC ranged from 10.5 in 1989 to 16.8 in 2004, and for proximal colon CRC from 5.4 in 1986 to 10.9 in 2007. Men $\geq 70$ years of age had the highest CRC mortality rates, regardless of the site of CRC in the colon (Table 1). The differences in rates between men and women were smaller for deaths due to proximal colon CRC than for distal colon CRC.

The choropleth maps depict the smoothed rates of CRC mortality across Manitoba, which ranged between 8.1 to 43.2 (per 100,000) in 1985 to 2009 (Figure 1). The highest CRC mortality rates were observed in the Northcentral part of Winnipeg and in rural areas in Southwestern and Eastern Manitoba, while Northern Manitoba had the lowest CRC mortality rates. Mortality rates from distal colon CRC ranged from 4.1 to 23.3 (per 100,000), with the highest distal colon CRC mortality rates in the northern part of Winnipeg and in discrete rural areas in eastern Manitoba (data not shown). The mortality rates from proximal colon CRC (1985 to 2009) ranged from 1.6 to 14.6 (per $100,000)$, with the highest rates observed in discrete areas of southern Winnipeg (data not shown). The mortality rates (overall, proximal colon and distal colon CRC) across Manitoba for the two different time periods 1985 to 1996 and 1997 to 2009 suggested that in the second time period of the study, there was an increase in the CRC mortality in the northern part of the province and in the northern part of Winnipeg (an area with higher proportion of immigrants from Southeast Asia and Indian subcontinent).

Overall, CRC mortality rates tended to decrease for both men and women over the study period (Table 2). However, changes in rates differed substantially depending on the mean household income of the

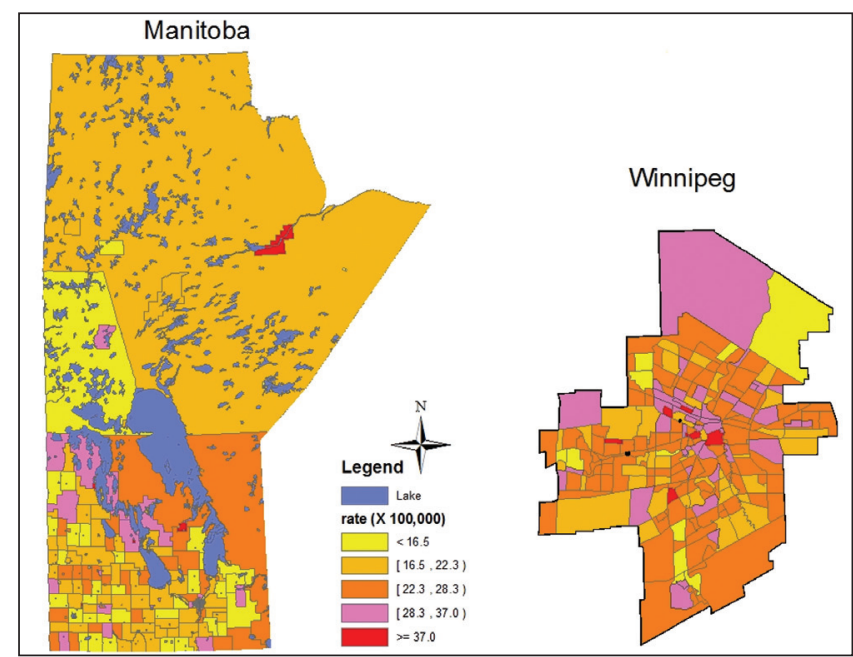

Figure 1) Smoothed colorectal cancer mortality rates (per 100,000) (all sites combined), province of Manitoba and city of Winnipeg, Manitoba, 1985 to 2009, age-and sex-adjusted to the 1991 Canadian population

area where individuals resided. Although men and women residing in areas with the highest annual income $(>\$ 85,000)$ had higher CRC mortality in the 1980s than those residing in the other neighbourhoods, they had a significant decrease in CRC mortality between 1985 and 2009 (APC approximately $-1.8 \%$ ), while those residing in areas with the lowest annual income $(<\$ 47,000)$ experienced an increase (APC men 1985 to 2009: +0.95; APC women 1985 to 1992: +8.07 and 1992 to 2009: +0.04) (Table 2; Figures 2A and 2B). The pairwise comparability tests suggest that the trend for the lowest income group was statistically significantly different than that of the other two income groups.

In the age- and sex-adjusted Poisson regression models for CRC mortality 1985 to 2009, the overall, proximal colon and distal colon CRC mortality rates among those living in the highest-income areas 


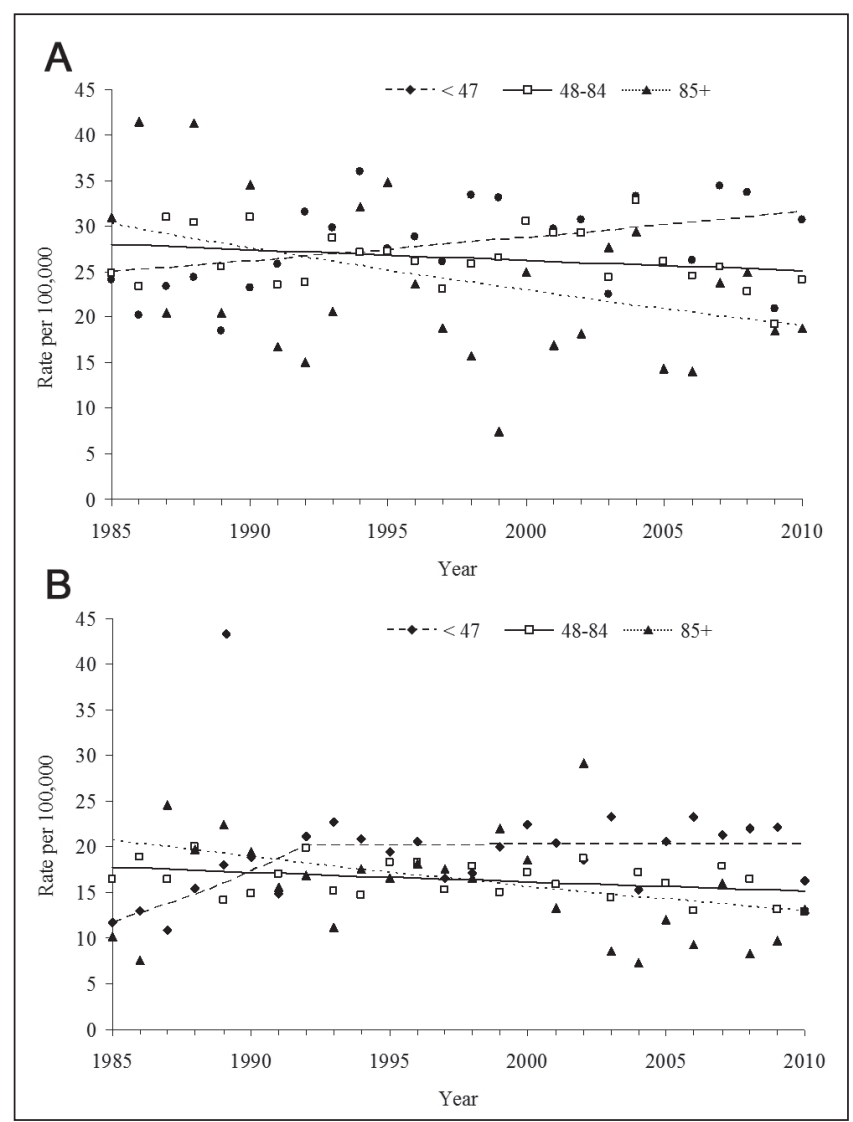

Figure 2) A Time trends of overall colorectal cancer mortality among men in different income groups (1985 to 2009), joinpoint regression analysis. B Time trends of overall colorectal cancer mortality among women in different income groups (1985 to 2009); joinpoint regression analysis

were approximately 20\% lower than those residing in the lowestincome areas (Table 3). There was no relationship to recent immigrant status or higher visible minorities' status. Areas with higher proportion of individuals of Jewish ethnicity did not experience increased CRC mortality. Individuals residing in the southern parts of the province had higher rates of death from proximal colon CRC.

The saturated Poisson regression analysis suggested that between 1985 and 2009, the highest CRC mortality rates occurred in Southcentral Manitoba (MRR 1.62) and Southeastern Manitoba (MRR 1.31) (regions of the province with higher proportion of individuals of Dutch-German Mennonite ethnic descent and farming communities) (Table 4). While the mean household income was not associated with CRC mortality rate in 1985 to 1996, areas with higher income experienced lower CRC mortality in 1997 to 2009. The impact of income was similar for deaths due to distal colon CRC and deaths due to proximal colon CRC. Geographical areas with a higher proportion of recent immigrants had lower CRC mortality; this reduction was essentially related to lower mortality due to distal colon CRC.

\section{DISCUSSION}

The present analysis highlights that individuals residing in higherincome areas in Manitoba experienced a decrease in CRC mortality over the study period while people residing in lower income areas experienced an increase. In the mid-1980s, individuals residing in lower income areas had lower mortality rates from CRC than people in higher income areas, which reversed over time.

We are not aware of a similar analysis in Canada, but comparable observations have been reported from the United States (5). SaldanaRuiz et al (5) reported that before 1980, people living in counties with higher average SES were at greater risk for dying from CRC than
TABLE 3

Age- and sex-adjusted Poisson regression analyses of colorectal cancer (CRC) mortality, 1985 to 2009

\begin{tabular}{|c|c|c|c|}
\hline & All CRC & Distal colon & Proximal colon \\
\hline \multicolumn{4}{|c|}{ Region (Manitoba) } \\
\hline Urban* & $1.03(0.98-1.0)$ & $1.02(0.95-1.09)$ & $1.07(0.98-1.17)$ \\
\hline Rural & $1.00(-)$ & $1.00(-)$ & $1.00(-)$ \\
\hline $\begin{array}{l}\text { Winnipeg } \\
\text { (excl core) }\end{array}$ & $1.00(-)$ & $1.00(-)$ & $1.00(-)$ \\
\hline Winnipeg core & $0.95(0.85-1.06)$ & $0.82(0.71-0.95)$ & $1.21(0.96-1.51)$ \\
\hline Northern & $0.89(0.78-1.01)$ & $0.80(0.68-0.94)$ & $1.12(0.86-1.44)$ \\
\hline Southwestern & $1.09(0.97-1.21)$ & $0.94(0.81-1.08)$ & $1.43(1.14-1.78)$ \\
\hline Southcentral & $1.19(1.07-1.34)$ & $1.04(0.89-1.19)$ & $1.54(1.23-1.93)$ \\
\hline Southeastern & $0.98(0.88-1.08)$ & $0.86(0.76-0.98)$ & $1.27(1.03-1.56)$ \\
\hline \multicolumn{4}{|c|}{ Annual income, \$ } \\
\hline$<47,000$ & $1.00(-)$ & $1.00(-)$ & $1.00(-)$ \\
\hline $\begin{array}{c}47,000 \text { to } \\
85,000\end{array}$ & $0.89(0.84-0.94)$ & $0.84(0.78-0.90)$ & $0.96(0.87-1.06)$ \\
\hline$>85,000$ & $0.80(0.72-0.88)$ & $0.79(0.69-0.90)$ & $0.79(0.65-0.93)$ \\
\hline \multicolumn{4}{|c|}{ Unemployment rate, \% } \\
\hline$<9$ & $1.00(-)$ & $1.00(-)$ & $1.00(-)$ \\
\hline 9 to $<19$ & $1.12(1.05-1.21)$ & $1.22(1.11-1.33)$ & $1.00(0.88-1.14)$ \\
\hline 19 to 35 & $1.09(0.97-1.21)$ & $1.28(1.11-1.46)$ & $0.69(0.54-0.88)$ \\
\hline \multicolumn{4}{|c|}{ Recent immigrants, \% } \\
\hline$<9$ & $1.00(-)$ & $1.00(-)$ & $1.00(-)$ \\
\hline 9 to $<20$ & $0.97(0.92-1.02)$ & $0.94(0.87-1.00)$ & $1.06(0.97-1.16)$ \\
\hline 20 to $<40$ & $0.95(0.88-1.01)$ & $0.93(0.85-1.02)$ & $1.06(0.93-1.19)$ \\
\hline \multicolumn{4}{|c|}{ Jewish ethnicity, \% } \\
\hline$<4$ & $1.00(-)$ & $1.00(-)$ & $1.00(-)$ \\
\hline 4 to $<13$ & $1.01(0.90-1.13)$ & $0.87(0.73-1.02)$ & $1.20(0.98-1.43)$ \\
\hline 13 to $<30$ & $0.84(0.72-0.88)$ & $0.85(0.68-1.04)$ & $0.87(0.65-1.12)$ \\
\hline \multicolumn{4}{|c|}{ Visible minorities, \% } \\
\hline$<6$ & $1.00(-)$ & $1.00(-)$ & $1.00(-)$ \\
\hline 6 to $<19$ & $1.06(1.00-1.11)$ & $1.04(0.97-1.11)$ & $1.12(1.02-1.23)$ \\
\hline 19 to $<48$ & $0.98(0.91-1.05)$ & $0.99(0.90-1.09)$ & $1.01(0.89-1.14)$ \\
\hline
\end{tabular}

Data presented as mortality rate ratio $(95 \% \mathrm{Cl})$. *Urban-rural differences were evaluated in a separate model. excl Excluding

individuals living in counties with lower SES. In that study, the gradient also reversed direction over time. Our initial hypothesis was that income would not be significantly associated with the risk of dying from CRC in Manitoba because of the universal health care system and because of efforts to diminish social inequity in the province. Far from supporting that notion, our results suggest a disconcerting scenario of widening SES gap in CRC mortality over time. In their study, Saldana-Ruiz et al (5) suggest that a framework of fundamental social causes ("resources that can be used to avoid risks or to minimize the consequences of disease once it occurs" [23]), including "money, knowledge, status and availability of social support" (5) may be used to understand gaps in health outcomes such as CRC mortality. The framework predicts that when a new resource becomes available (eg, screening for cancer), it will be more readily accessed by people who already have resources, leading to earlier and more rapid reduction in disease incidence and mortality in that group. Our results suggest that this framework could also be applicable to a jurisdiction with a universal health care system. The widening gap in CRC mortality among socioeconomic groups could be due to earlier access to knowledge regarding screening among the higher income groups. A recent report from Ontario (24) suggests that the inequities in CRC screening participation according to SES in Ontario may have increased between 2005 and 2011, despite the launch of province-wide CRC screening program in 2008.

Our observation that the differences with income were no more marked for deaths from distal colon CRC suggests there may be additional contributing factors because $\mathrm{CRC}$ screening in usual clinical 
TABLE 4

Adjusted saturated Poisson regression analysis of colorectal cancer (CRC) mortality

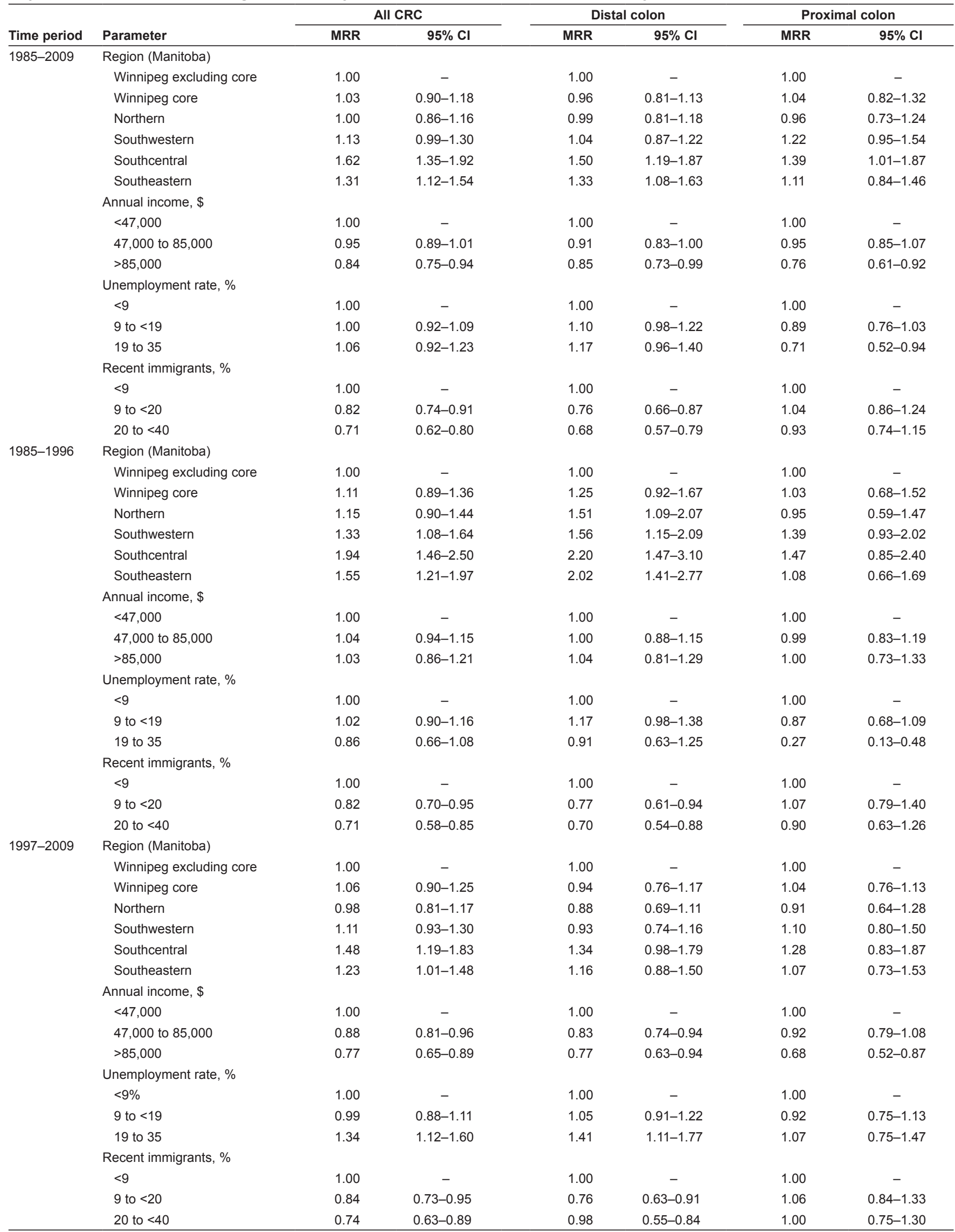

Cl Credible interval; MRR Mortality rate ratio 
practice is more effective in preventing deaths from distal colon CRC (12). These factors may include changes over time in CRC lifestyle risk factors (eg, obesity), receipt of treatment and survival after CRC diagnosis, and should be investigated. The important implication of the fundamental social causes framework for policy makers includes significantly more emphasis when introducing new organized screening programs and treatments on ensuring equal uptake among lower socioeconomic groups. To the best of our knowledge, the Canadian provincial CRC screening programs have not, to date, made extra efforts to encourage CRC screening among lower SES groups. Our results, combined with that from the recent study from Ontario (24), emphasize the urgent need for such efforts. We suggest that all recently established Canadian provincial CRC screening should investigate the SES inequities in CRC screening participation in their jurisdictions and develop measures to reduce any such disparities.

In the saturated regression models, we found that southcentral and southeastern regions in the province had a higher CRC mortality rate. Differences in the ethnic composition of the populations could be contributing to this pattern. There are a higher proportion of individuals of Dutch-German Mennonite ethnic descent in these regions. A specific genetic mutation has been described in several families of Mennonite background in Manitoba (25), which has been associated with Lynch syndrome, a hereditary syndrome with very high risk for developing CRC. Although a $40 \%$ to $60 \%$ lifetime risk of CRC has been suspected in families with this mutation (26), we do not know the prevalence of this mutation in our population. Additional studies should investigate the reasons for the regional variations in CRC mortality and assess whether there are variations in CRC incidence, stage at presentation and survival after CRC diagnosis.

It is interesting to note that areas with higher proportions of recent immigrants had lower mortality rates from CRC in the analysis adjusted for income, but not in the analysis adjusted for age and sex only. This finding may have some implications for the CRC screening programs, which may be concerned about potentially lower rates of CRC screening among the immigrant populations. Our results suggest the focus should be on areas with lower income, irrespective of the proportion of recent immigrants among their inhabitants.

The results of our study should be interpreted in the context of its strengths and limitations. We used Bayesian Poisson mixed models to obtain stable rate estimates for areas with small case counts. We used the population-based MCR, which has been found to have very high data quality $(8,9)$. We accessed the Manitoba Population Registry, which is regularly updated and, hence, had comprehensive follow-up. Our multiple regression analysis to determine the effect of average household income included variables indicating different regions of the province, thereby adjusting for potential regional variations in delivery of health care. The cause-of-death data from Manitoba Vital Statistics was supplemented by the data on CRC mortality by an algorithm to identify additional cases of CRC mortality. The routine, careful evaluation of each cancer death by the Manitoba Cancer Registry has enabled us to develop and use such an algorithm in this and previous studies (12).

On the other hand, the present study was an ecological analysis and additional studies are needed to confirm its findings. Although previous studies from Manitoba have shown a substantial correlation between self-reported household income and an individual's neighbourhood average income (27), the increase in CRC mortality among those residing in the lowest income neighbourhood found in the present study should be interpreted in the context of average neighbourhood household income and suggests the potential importance of focusing on lower-income neighbourhoods. The present study was observational in nature, a study design that has the potential for residual confounding by unmeasured or unrecognized factors. We were not able to evaluate the effect of ethnicity independent of income. We used the data from a single census year (2001) to determine the ecological characteristics. However, most important variables, such as relative average neighbourhood income, have not changed over time.
We did not adjust our analyses for CRC stage at diagnosis because for most of the study, period stage information was not collected reliably by the Registry (routinely collected from 2004 onward). However, stage is likely a mediator of the effects of SES differences on mortality; therefore, adjusting for it will only serve to explain at least some of the differences, but will not change the conclusions.

\section{CONCLUSION}

We identified regional variations in CRC mortality in Manitoba and widening SES gap in CRC mortality between income groups. The results suggest that SES disparities in CRC mortality could exist or even increase over time, even in jurisdictions with a universal health care system. The results also suggest that lower income areas should be a focus of CRC screening programs and other health care programs aiming to reduce the health burden of CRC.

DISCLOSURES: Dr Torabi was supported by an establishment grant from Manitoba Health Research Council (MHRC). Dr Mahmud holds a Canada Research Chair in Pharmacoepidemiology and Vaccine Research, and was supported by an establishment grant from the MHRC and by the Great-West Life, London Life and Canada Life Junior Investigator Award from the Canadian Cancer Society. The results and conclusions are those of the authors, and no official endorsement by CancerCare Manitoba or Manitoba Health is intended or should be inferred. There are no conflicts of interest. The analyses were performed by Drs Torabi and Nugent. All of the authors were involved in the study concept and design; acquisition of data, interpretation of data and critical revision of the manuscript for important intellectual content.

\section{REFERENCES}

1. Canadian Cancer Society's Steering Committee. Canadian Cancer Statistics 2012. Toronto: Canadian Cancer Society, 2012.

2. Zauber AG, Winawer SJ, O’Brien MJ, et al. Colonoscopic polypectomy and long-term prevention of colorectal-cancer deaths. N Engl J Med 2012;366:687-96.

3. Hewitson P, Glasziou P, Watson E, et al. Cochrane systematic review of colorectal cancer screening using the fecal occult blood test (hemoccult): An update. Am J Gastroenterol 2008;103:1541-9.

4. Moynihan R, Doust J, Henry D. Preventing overdiagnosis: How to stop harming the healthy. BMJ 2012;344:e3502.

5. Saldana-Ruiz N, Clouston SA, Rubin MS, Colen CG, Link BG. Fundamental causes of colorectal cancer mortality in the United States: Understanding the importance of socioeconomic status in creating inequality in mortality. Am J Public Health 2013;103:99.

6. Steinbrecher A, Fish K, Clarke CA, et al. Examining the association between socioeconomic status and invasive colorectal cancer incidence and mortality in California. Cancer Epidemiol Biomarkers Prev 2012;21:1814-22.

7. Roos LL, Walld R, Uhanova J, et al. Physician visits, hospitalizations, and socioeconomic status: Ambulatory care sensitive conditions in a Canadian setting. Health Services Res 2005;40:1167-85.

8. Hotes Ellison J, Wu XC, McLaughlin C, et al, eds. Cancer in North America: 1999-2003. Vol 1: Incidence: North American Asociation of Central Cancer Registeries Inc, 2006:II-325.

9. Chen VW, Wu XC. Incidence, cancer in North America, 1991-1995. In: Andrews PA, ed. North American Association of Cancer Registries. Sacramento, 1999.

10. Iacopetta B. Are there two sides to colorectal cancer? Int J Cancer 2002;101:403-8.

11. Nawa T, Kato J, Kawamoto H, et al. Differences between right- and left-sided colon cancer in patient characteristics, cancer morphology and histology. J Gastroenterol Hepatol 2008;23:418-23.

12. Singh H, Nugent Z, Demers AA, et al. The reduction in colorectal cancer mortality after colonoscopy varies by site of the cancer. Gastroenterology 2010;139:1128-37.

13. Baxter NN, Goldwasser MA, Paszat LF, et al. Association of colonoscopy and death from colorectal cancer. Ann Intern Med 2009;150:1-8.

14. Atkin WS, Edwards R, Kralj-Hans I, et al. Once-only flexible sigmoidoscopy screening in prevention of colorectal cancer: A multicentre randomised controlled trial. Lancet 2010;375:1624-33. 
15. Haug U, Knudsen AB, Brenner H, et al. Is fecal occult blood testing more sensitive for left- versus right-sided colorectal neoplasia? A systematic literature review. Exp Rev Molecul Diagnos 2011;11:605-16.

16. Singh H, Demers AA, Xue L, et al. Time trends in colon cancer incidence and distribution and lower gastrointestinal endoscopy utilization in Manitoba. Am J Gastroenterol 2008;103:1249-56.

17. Locker GY, Lynch HT. Genetic factors and colorectal cancer in Ashkenazi Jews. Fam Cancer 2004;3:215-21.

18. Torabi M, Rosychuk RJ. Hierarchical Bayesian spatiotemporal analysis of childhood cancer trends. Geogr Anal 2012;44:109-20.

19. Torabi M. Hierarchical Bayes estimation of spatial statistics for rates. J Statist Planning Inference 2012;142:358-65.

20. Jenks GF. The Data Model Concept in Statistical Mapping. International Yearbook of Cartography 1967;7:186-90.

21. Canadian Cancer Society's Steering Committee. Canadian Cancer Statistics 2011. Toronto: 2011.
22. Kim H-J, Fay MP, Yu B, et al. Comparability of segmented line regression models. Biometrics 2004;60:1005-14.

23. Link BG, Phelan J. Social conditions as fundamental causes of disease. J Health Soc Behav 1995;Spec No:80-94.

24. Honein-AbouHaidar GN, Baxter NN, Moineddin R, et al. Trends and inequities in colorectal cancer screening participation in Ontario, Canada, 2005-2011. Cancer Epidemiol 2013;37:946-56.

25. Lwiwski N, Greenberg CR, Mhanni AA. Genetic testing of children at risk for adult onset conditions: When is testing indicated? J Gen Counsel 2008;17:523-5.

26. Orton NC, Innes AM, Chudley AE, et al. Unique disease heritage of the Dutch-German Mennonite population. Am J Med Gen 2008;146A:1072-87.

27. Mustard CA, Derksen S, Berthelot J-M, et al. Assessing ecologic proxies for household income: A comparison of household and neighbourhood level income measures in the study of population health status. Health Place 1999;5:157-71. 


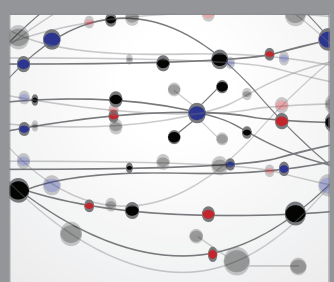

The Scientific World Journal
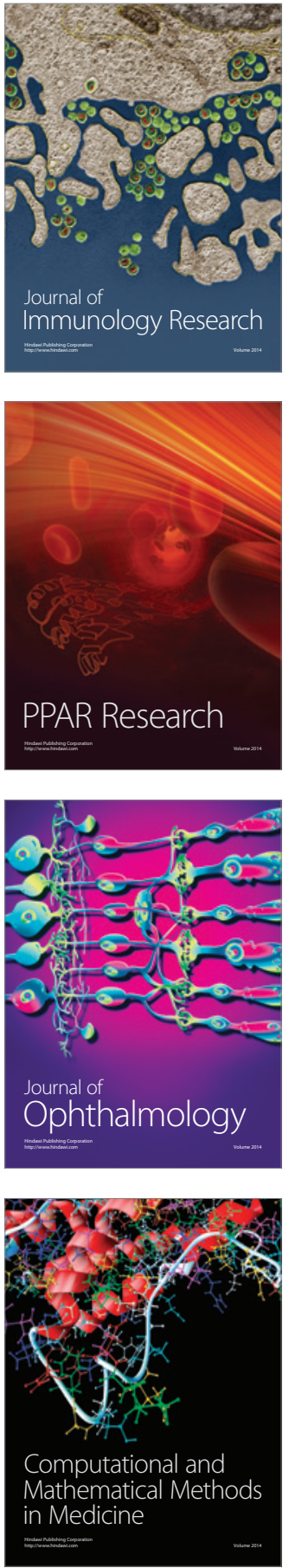

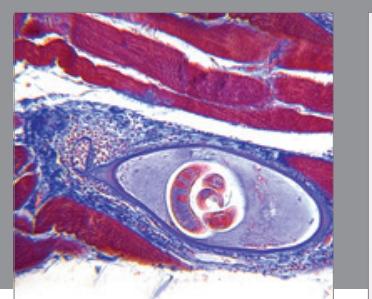

Gastroenterology Research and Practice

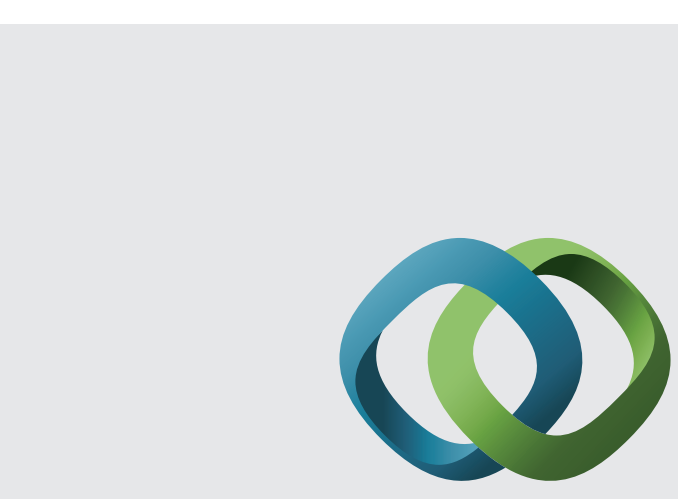

\section{Hindawi}

Submit your manuscripts at

http://www.hindawi.com
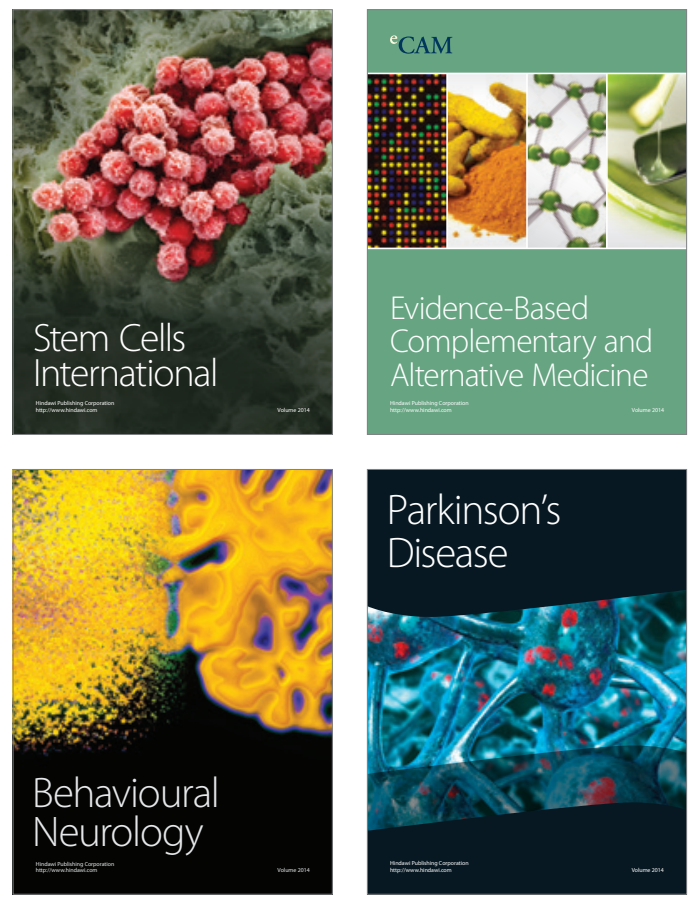
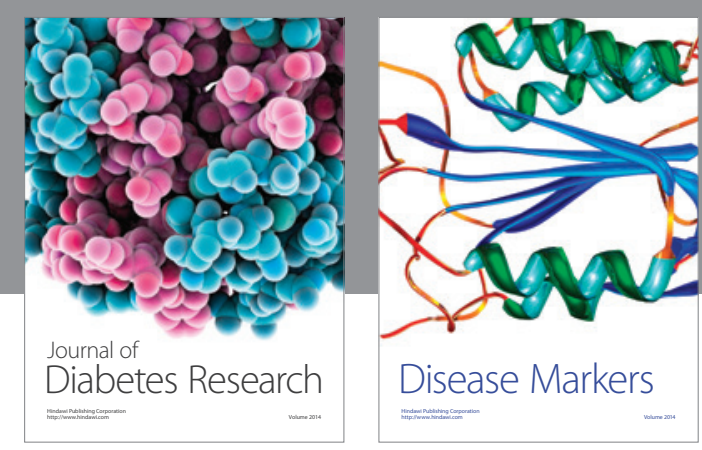

Disease Markers
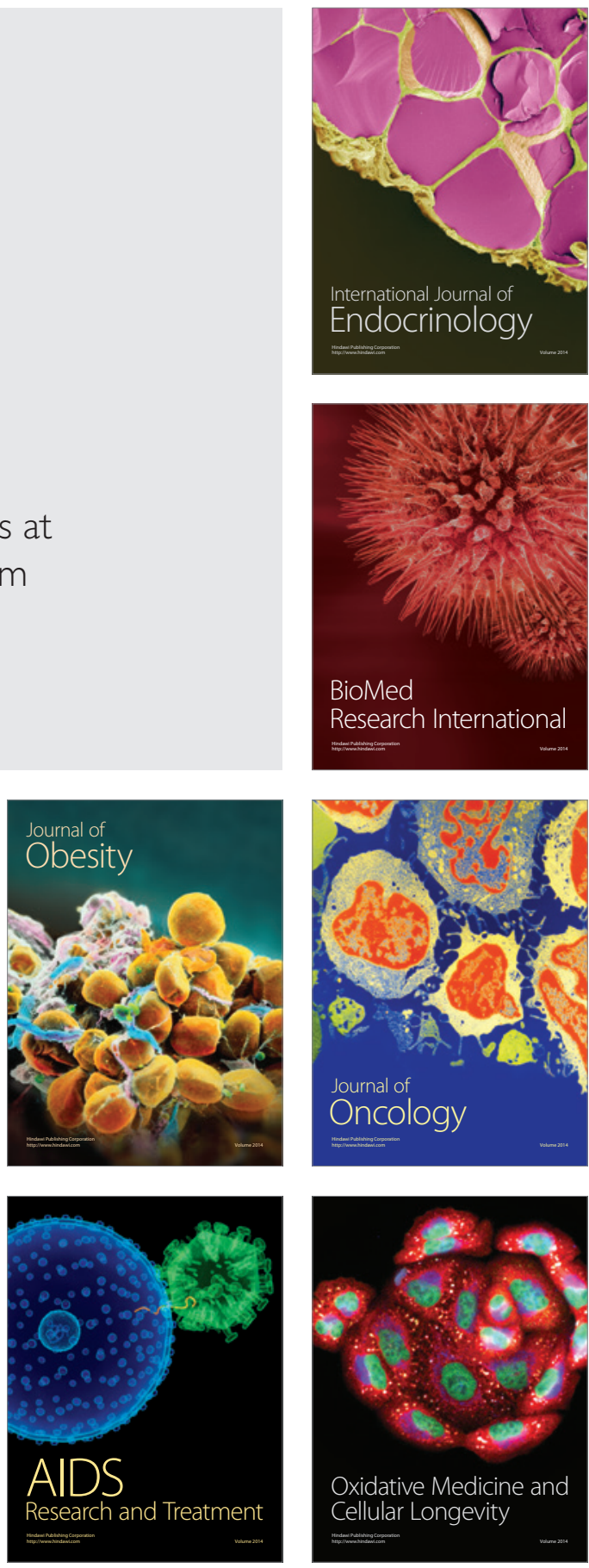